\title{
Measuring the True Human Cost of Natural Disasters
}

\author{
Lynn Lawry, MD, MSPH, MSc, and Frederick M. Burkle, Jr, MD, MPH, DTM
}

$\mathrm{B}$ runkard and colleagues provide a detailed assessment of direct mortality rates in Louisiana from Hurricane Katrina, the deadliest hurricane to strike the US Gulf Coast since $1928 .{ }^{1}$ The authors should be commended on their efforts because this solidly contributes to the evidencebased literature, but the scope of this examination needs to be expanded if we are to calculate the true human cost of the event.

When examined contextually, the destructive effects of Hurricane Katrina meet or exceed most natural disasters in recent history. This event internally displaced more than 2.5 million people throughout the United States, at the time representing $10 \%$ of the world's total 25 million internally displaced persons (IDP). ${ }^{2}$ These figures were equivalent to the numbers of IDP in Darfur, Sudan, and more than the estimated 1.5 million IDP in all of the countries affected by the 2004 Indian Ocean tsunami. ${ }^{3}$ Ultimately more than 85,000 people were placed in temporary housing in trailer parks (trailers provided by the Federal Emergency Management Agency [FEMA]), located mostly in Louisiana and Mississippi, ${ }^{2}$ with 45,000 of these individuals continuing to live in the FEMA trailers. ${ }^{4}$

Even these formidable numbers may underestimate the true burden created by Katrina and other large-scale disasters. Researchers are inherently hindered in their ability to estimate human costs accurately due to the practical difficulties in finding, assessing, and measuring mortality and morbidity from the people affected, who are often silent and unrecognized.

Conventional disaster assessments typically measure mortality only for a period of a few weeks and solely examine direct consequences. Mortality, classified for assessment purposes as "direct deaths," include deaths caused by the environmental or physical forces of the disaster (eg, drowning in floodwaters, injuries sustained from flying debris, head injury from structural damage). Although the timeframe is characteristically immediate, these assessments do include delayed deaths that result from the initial injury. ${ }^{5}$

These assessments fail to account for "indirect deaths" that in reality will contribute to a large percentage of the excess mortality. We know from years of international disasters that the greatest human losses, as high as $70 \%$ to $90 \%$, are secondary to deaths attributable to the breakdown of health and social services, health information (surveillance) systems, mass displacement of populations, overcrowded or poor temporary living conditions, and the loss of livelihoods. ${ }^{6}$ Indirect deaths also encompass a wide range of causes that make surveillance more difficult, including suicide and homicide, accidents during the recovery phase, motor vehicle accidents during relocations, cardiovascular deaths that occur as a result of shock or stress, and exacerbation of preexisting medical conditions that cannot be addressed due to many public health infrastructure and system failures (including but not limited to medical record loss, insurance lapses, and the destruction of medical facilities in the disaster area). ${ }^{5}$

Unlike immediate direct deaths, the accumulation of indirect deaths can continue long after the initial impact of the disaster. This phenomenon, which is recognized internationally, can precipitate a public health emergency, often referred to as "excess mortality." These deaths are expressed as the difference between observed and noncrisis mortality rates or as a total number of excess deaths and are commonly used as an advocacy and/or political tool, particularly in conflict environments. ${ }^{7}$ Alternatively, others have suggested a third classification: "disaster-triggered deaths." These deaths result from disruption of care up to 1 year postdisaster and are classified as such in an attempt to capture the impact of poor chronic disease management; here, the interaction of stress and underlying physical or mental long-term surveillance is especially important. ${ }^{5}$ Regardless of the nomenclature, the disaster community must keep in mind that indirect deaths are preventable and can be averted with adequate surveillance and planning.

Assessing postdisaster mortality among refugees and IDP in international disasters is achieved through the use of a crude mortality rate (CMR) or the under-five mortality rate (U5MR) as key indicators to define an emergency. For reference baseline, noncrisis CMRs in most of subsaharan Africa range from 0.3 to $0.6 / 10,000 /$ day. A doubling of CMR (to $1 / 10,000 /$ day) represents the internationally accepted threshold for formally declaring a health emergency. ${ }^{7} \mathrm{CMR}$ and U5MR alone, however, may not help to clearly identify specific gaps in the humanitarian response or the causes of the indirect mortality. For most causes of death, a reduction 
in mortality is the result of multisector interventions. For example, a decreased mortality rate from acute respiratory infections can be the result of improved shelter, greater access and availability to outpatient and inpatient care, better nutrition, and improved livelihood. ${ }^{?}$

Unfortunately, the Katrina catastrophe represented a public health emergency for which indirect deaths were not recognized or appreciated in a timely manner. Katrina highlighted and exposed the deficiency and deterioration in essential public health and health care services in the Mississippi Delta region. Before the 2005 hurricane season, health and well-being indicators ranked Louisiana as the least healthy state in the United States, ${ }^{8}$ and Mississippi was ranked 49th of 50 states. ${ }^{8}$ Within these 2 states, approximately 1 in 5 people do not have health insurance, and both states rank in the top 5 for highest rates of HIV/AIDS, tuberculosis, sexually transmitted diseases, crude death rates, and infant mortality. ${ }^{9}$

As the population density of this region increased, ${ }^{10}$ the inadequacy of public health systems, coupled with aging and poorly maintained levees, ${ }^{11}$ facilitated the rapid accumulation of indirect deaths. In fact, it is normally human system failures in public health infrastructure, civil infrastructure, and coordination that greatly contribute to the indirect effects of natural disasters, all of which are preventable.

Studies show that mortality rates after a natural disaster generally increase in the first three days and return to baseline. ${ }^{12}$ Brunkard and colleagues show that 986 people were directly killed by Hurricane Katrina. This is also a conservative figure, considering the inadequacies of surveillance during and after the event. But what do we know about indirect deaths as a result of Hurricane Katrina? Using death notices in a local New Orleans newspaper, Stephens et al found the mortality rate for New Orleans in the first 6 months of 2006 was approximately 91.37 deaths per 100,000 population $(0.5$ deaths per day $/ 10,000$ population), compared to the preKatrina population mortality rate of 62.17 deaths per 100,000 population ( 0.3 deaths per day/10,000 population). This represented a $47 \%$ increase from the baseline mortality, suggesting a marked increase in indirect (excess) deaths postdisaster. ${ }^{13}$ This increase suggested that the weakened public health infrastructure and surveillance system no longer had the capacity to identify health problems in a timely fashion and contributed to the resulting excess mortality.

Prehurricane crude mortality rates or baseline CMR rates for Louisiana and Mississippi were 941 and 990/100,000, respectively, or approximately 0.27 deaths per day/10,000 population, close to noncrisis subsaharan CMRs. ${ }^{7,9}$ Larrance et $\mathrm{al}^{2}$ documented a mortality rate of 0.87 deaths per day $/ 10,000$ among those in FEMA trailers in Mississippi and Louisiana 1 year after the disaster. This figure is higher than the 6 -month rates found by Stephens et al, and was nearly double the baseline rates, which is similar to the internationally accepted threshold for formally declaring a health emergency. ${ }^{7}$ Furthermore, this rate may have been an underestimation because the 2-week assessment period assessed may have been insufficient to capture mortality rates accurately. ${ }^{2}$

In another survey, Shehab and colleagues documented factors contributing to these indirect mortality rates among Mississippi FEMA trailer residents 2 years after the disaster. ${ }^{4}$ This study demonstrated significant numbers of households with at least 1 adult with a chronic disease and at least 1 child with a chronic disease. In addition, significant numbers of the Mississippi FEMA trailer population fit the criteria for major depressive disorder, with a smaller subset reporting suicidal ideation and attempts. It is notable that the vast majority reported no access to mental health services. It was also found that fewer than half of the households had health insurance and many delayed health care due to lack of insurance or money to pay for health care visits. Finally, unpublished data from the same study revealed a 2-year mortality rate of 0.38 deaths per day/10,000 population; less than the 1 -year CMR but still not at the prehurricane baseline rates. (Using a 90-day recall period, 6 household members, representing an estimated $1 \%$ of the population, were reported to have died. According to this rate, we would expect 42.6 deaths (3.8 deaths/day/100,000 population) among 12,377 people during the 90-day period assessed or 42.6/ $12,377 \times 10,000 / 90$ days $=0.38 / 10,000$ per day.

In acknowledging the direct and indirect effects of natural disasters, disaster planners should develop surveillance systems that are sensitive to the true human cost of disasters. In doing so, recovery programs can be better tailored to address the basic human needs of food, shelter, security, clean water, education, and basic health and mental health care access. When implemented and executed in a timely fashion, these public health infrastructure improvements can better reduce overall mortality. ${ }^{14,15}$

\section{About the Authors}

Dr Lawry is Senior Health Stability/Humanitarian Assistance Specialist, International Health Division, Office of the US Assistant Secretary of Defense (Health Affairs); Dr Burkle, a Woodrow Wilson International Scholar, is Senior Fellow, HarvardHumanitarian Initiative, Harvard University.

Address correspondence and reprint requests to Dr Lynn Lawry, International Health Division, Office of the Assistant Secretary of Defense (Health Affairs), 5205 Leesburg Pike (Sky 1), Suite 810, Falls Church, VA 22041(e-mail: llawry@cdham.org).

Received and accepted for publication August 18, 2008.

\section{Authors' Disclosures}

The authors report no conflicts of interest.

ISSN: 1935-7893 (C) 2008 by the American Medical Association and Lippincott Williams \& Wilkins.

DOI: 10.1097/DMP.0b013e31818adaa2

\section{REFERENCES}

1. Brunkard J, Ratard R, Namulanda G, et al. Hurricane Katrina deaths, Louisiana, 2005. Disaster Med Public Health Preparedness. 2008;2.

2. Larrance R, Anastario M, Lawry L. Health status among internally 
displaced persons in Louisiana and Mississippi travel trailer parks: a global perspective. Annals Emer Med. 2007; 49: 590-601.

3. Internal Displacement Monitoring Centre. Internal displacement: global overview of trends and developments in 2005.http:// www.internal-displacement.org/8025708F004CE90B/(httpPages)/ 22FB1D4E2B196DAA802570BB005E787C?OpenDocument $=1000$. Accessed August 21, 2008.

4. Shehab N, Anastario M, Lawry L. Health assessment and health care access among internally displaced persons in Mississippi travel trailer parks two years after the 2005 Gulf Coast hurricane season. Health Affairs. 2008;27:w416-w429 (published online August 29, 2008; 10.1377/hlhaff.27.5.w416).

5. Usher-Pines L. "But for the hurricane": measuring natural disaster mortality over the long term. Prehosp Disaster Med. 2007;22:149-153.

6. Burkle F, Greenough G. Impact of public health emergencies on modern disaster taxonomy, planning, and response. Disaster Med Public Health Preparedness. 2008;2:192-199.

7. Checchi F, Roberts L. Interpreting and using mortality data in humanitarian emergencies: a primer for non-epidemiologists. $h t t p: / / w w w . r e l i e f w e b . i n t / r w /$ lib.nsf/db900SID/OCHA-6GLHKS?OpenDocument. Published September 2005. Accessed August 21, 2008.

8. Center for American Progress. Katrina by the numbers: need for health care assistance in Louisiana. http://www. americanprogress.org/issues/2005/ 10/b1101085.html. Published October 7, 2005. Accessed August 21, 2008.

9. Louisiana Department of Health and Hospitals.2005 Louisiana health report card. http://www.dhh.louisiana.gov/offices/reports.asp? $I D=275$ ED Detail $=473$. Accessed August 21, 2008.

10. Demographia. http://www.demographia.com/db-uscity98.htm. Accessed August 16, 2008.

11. Seed RB, Bea RG, Abdelmalak RI, et al. The Independent Levee Investigation Team. Investigation of the Performance of the New Orleans Flood Protection Systems in Hurricane Katrina on August 29, 2005. http://www. ce.berkeley.edu/new_orleans. Published July 31, 2006. Accessed August 16, 2008.

12. Nishikiori N, Abe T, Costa DG, et al Timing of mortality among internally displaced persons due to the tsunami in Sri Lanka: crosssectional household survey. BMJ. 2006;332:334-335.

13. Stephens KU, Grew D, Chin K, et al. Excess mortality in the aftermath of Hurricane Katrina: a preliminary report. Disaster Med Public Health Preparedness. 2007;1:5-20.

14. Mann M, Gruskin S, Grodin M, et al. Health and Human Rights. Vol 8 . New York: Routledge; 1999.

15. United Nations. Universal Declaration of Human Rights. Adopted and proclaimed by UN General Assembly Resolution 217A (III) (December 10, 1948). http://www.un.org/Overview/rights.html. Accessed August 21, 2008. 